\title{
Bimetallic Metal-Organic Framework Mediated Synthesis of Ni-Co Catalysts for the Dry Reforming of Methane
}

\author{
Il Son Khan, Adrian Ramirez *(1), Genrikh Shterk, Luis Garzón-Tovar@ and Jorge Gascon * \\ Advanced Catalytic Materials, KAUST Catalysis Center (KCC), King Abdullah University of Science and \\ Technology, Thuwal 23955, Saudi Arabia; ilson.khan@kaust.edu.sa (I.S.K.); genrikh.shterk@kaust.edu.sa (G.S.); \\ luis.garzontovar@kaust.edu.sa (L.G.-T.) \\ * Correspondence: adrian.galilea@kaust.edu.sa (A.R.); jorge.gascon@kaust.edu.sa (J.G.)
}

Received: 30 April 2020; Accepted: 15 May 2020; Published: 25 May 2020

check for updates

\begin{abstract}
Dry reforming of methane (DRM) involves the conversion of $\mathrm{CO}_{2}$ and $\mathrm{CH}_{4}$, the most important greenhouse gases, into syngas, a stoichiometric mixture of $\mathrm{H}_{2}$ and $\mathrm{CO}$ that can be further processed via Fischer-Tropsch chemistry into a wide variety of products. However, the devolvement of the coke resistant catalyst, especially at high pressures, is still hampering commercial applications. One of the relatively new approaches for the synthesis of metal nanoparticle based catalysts comprises the use of metal-organic frameworks (MOFs) as catalyst precursors. In this work we have explored MOF-74/CPO-27 MOFs as precursors for the synthesis of $\mathrm{Ni}$, $\mathrm{Co}$ and bimetallic Ni-Co metal nanoparticles. Our results show that the bimetallic system produced through pyrolysis of a Ni-Co@CMOF-74 precursor displays the best activity at moderate pressures, with stable performance during at least $10 \mathrm{~h}$ at $700{ }^{\circ} \mathrm{C}, 5 \mathrm{bar}$ and $33 \mathrm{~L} \cdot \mathrm{h}^{-1} \cdot \mathrm{g}^{-1}$.
\end{abstract}

Keywords: metal-organic frameworks; MOF; dry reforming; catalysis

\section{Introduction}

With increasing concerns about $\mathrm{CO}_{2}$ emissions, research around the world has proposed several alternatives to convert this greenhouse gas into valuable commodities [1,2]. Probably one of the most convenient alternatives is the dry reforming of methane (DRM), which utilizes both $\mathrm{CH}_{4}$ and $\mathrm{CO}_{2}$ to produce syngas $\left(\mathrm{CO}+\mathrm{H}_{2}\right)$, which can be further converted to valuable building blocks and fuels $[3,4]$. The fact that $\mathrm{CH}_{4}$ instead of $\mathrm{H}_{2}$ is used to reduce $\mathrm{CO}_{2}$ makes this process especially attractive [5]. Over the years, multiple catalytic systems for the DRM based on noble metals ( $\mathrm{Pt}, \mathrm{Pd}$, $\mathrm{Rh}$, etc. [4]) have been reported, but their high cost and low abundance limited their industrial application. In this spirit, research has shifted to transition metals $(\mathrm{Ni}, \mathrm{Co}, \mathrm{Fe}$, etc.). However, they suffer severe drawbacks such as deactivation, metal particles sintering and inability to regenerate spent catalysts [6,7]. One proposed solution is the use of bimetallic Ni-Co systems as they show better carbon resistance due to synergistic effects $[8,9]$. In the same line, Yavuz et al. Recently reported a Ni-Mo bimetallic nanocatalysts on single-crystalline $\mathrm{MgO}$ that overcome all these issues, with stable activity and no detectable coking for more than $200 \mathrm{~h}[10,11]$. In spite of these very important advancements in the field, the development of catalysts able to operate in a stable manner at moderate to high pressures to reduce the resulting syngas compressing costs is still very important, yet hardly studied.

One class of materials that could close the gap between the research and the industrial application can be the relatively new crystalline porous materials consisting of metal cations nodes and organic linkers, known as metal-organic frameworks (MOFs). MOFs have received great interest on different applications $[12,13]$ including heterogeneous catalysis $[14,15]$ as the structural diversity, porous 
nature and tunability of both organic and inorganic parts $[16,17]$ offer great advantages over conventional synthesis methods. One of the most promising approaches for the synthesis of MOF-based heterogeneous catalysts is thermal carbonization under inert atmosphere [18]. This synthetic path opens new horizons in the controllable synthesis of highly dispersed mono- or multi-metallic nanoparticles (MNP) covered by a carbon shell with high metallic content and relatively high surface area in comparison to conventional supports [19]. These materials showed promising catalytic applications in different reactions such as Fischer-Tropsch synthesis, $\mathrm{CO}_{2}$ hydrogenation, dehydrogenation of paraffins and in the oxidation of organic molecules as well as $\mathrm{CO}$ [20-23]. However, these novel unique structures have not been applied yet to the DRM reaction. We speculated that the resulting carbon shell of the MOF mediated catalysts could be the main reason as, in a highly coke forming reaction as the DRM, it is expected that this carbon can trigger the formation of additional carbon/coke. Nevertheless, it has been shown before that carbon-supported nickel catalysts are viable for the DRM reaction [24], with even synergistic effects between the carbonaceous component and the metal-based fraction [25].

Hence, in this work we synthesized $\mathrm{Ni}$, Co and Ni-Co MOF-74/CPO-27 metal-organic frameworks and, by a simple pyrolysis treatment, demonstrated the application of Ni-Co MOF-derived materials as a novel catalyst in the DRM operation at moderate pressures. Among all the variety of MOFs structures, we chose the MOF-74/CPO-27 family due to its ability to have up to 10 different metal nodes arbitrarily located in the framework [26]. Our results show that the bimetallic Ni-Co catalyst outperformed the monometallic samples, displaying stable performance and no deactivation during at least $10 \mathrm{~h}$ at $700{ }^{\circ} \mathrm{C}, 5$ bar and $33 \mathrm{~L} \cdot \mathrm{h}^{-1} \cdot \mathrm{g}^{-1}$.

\section{Results and Discussion}

\subsection{Synthesis of the MOF Mediated Catalysts}

Synthesis of the MOF (Ni, Co and Ni-Co MOF-74) precursors was conducted following a slightly modified procedure from that reported by Garzón-Tovar et al. [27]. Briefly, we prepared a water solution of $\mathrm{NaOH}$ and 2,5-dihydroxyterephthalic acid (DHTA) with a 4:1 molar ratio. Afterwards, the mixture was poured inside a glass vial with two equivalents of the metal salt solution in water. The final mixture was kept overnight under stirring at room temperature and further filtrated. The X-ray diffraction (XRD) patterns (Figure 1a) and $\mathrm{N}_{2}$ adsorption data (Table 1 and Figures S1-S3) of the resulting solids revealed the formation of the desired MOFs. Next, the pyrolysis of the MOFs was conducted in a quartz tubular reactor vertically placed in a tube furnace. In a typical experiment, the MOFs were placed in the reactor under continuous flow of $\mathrm{N}_{2}$ followed by direct carbonization at $750{ }^{\circ} \mathrm{C}$ for $8 \mathrm{~h}$ under $\mathrm{N}_{2}$. Finally, after cooling the solid was passivated under a $5 \%$ oxygen in $\mathrm{N}_{2}$ flow.

Table 1. BET and inductively coupled plasma (ICP)-MS results of the metal-organic frameworks (MOFs) mediated catalysts.

\begin{tabular}{ccc}
\hline Materials & $\mathbf{S}_{\text {BET }}\left(\mathbf{m}^{\mathbf{2}} \mathbf{g}^{\mathbf{1}}\right)$ & Metal wt $\mathbf{~}$ \\
\hline Co-MOF-74 & 944 & 29 \\
Ni-MOF-74 & 1149 & 32 \\
Ni-Co-MOF-74 & 479 & $16 / 17$ \\
Co@CMOF-74 & 265 & 68 \\
Ni@CMOF-74 & 230 & 69 \\
Ni-Co@CMOF-74 & 178 & $33 / 35$ \\
\hline
\end{tabular}


a)

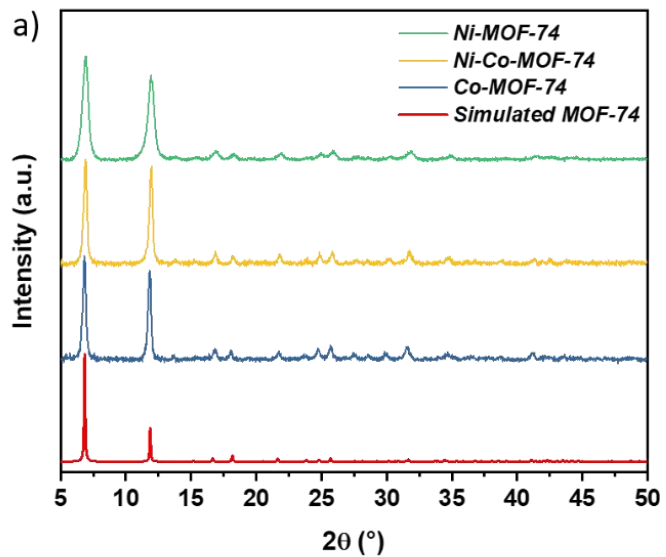

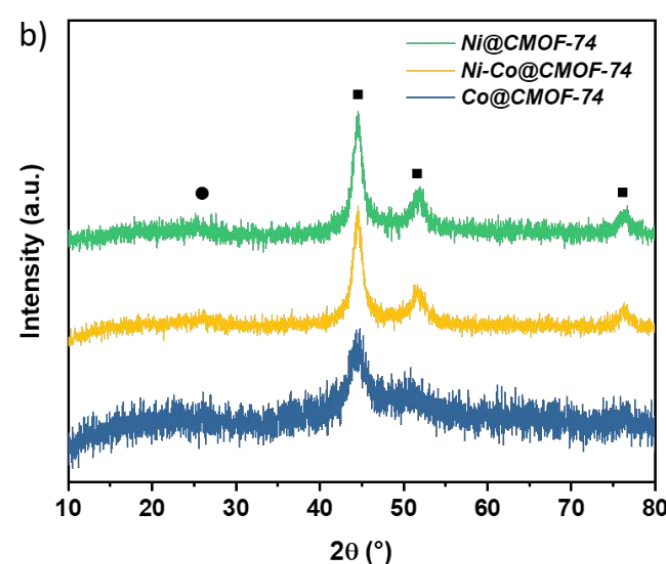

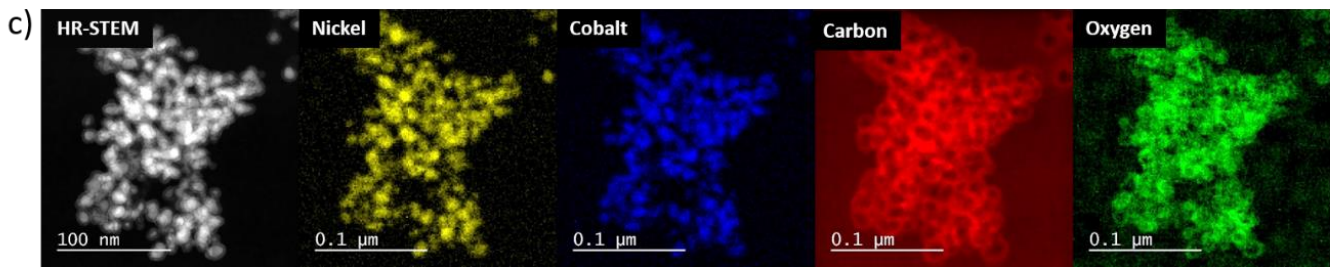

Figure 1. (a) Powder X-ray diffraction (PXRD) patterns of M-MOF-74 powders as compared to the corresponding simulated powder pattern of MOF-74; (b) powder X-ray diffraction (PXRD) patterns of M@CMOF-74 powders (•-graphite, $\mathbf{\square - M N P )}$ and (c) high-resolution dark field scanning transmission electron microscopy (STEM) image of Ni-Co@CMOF-74 catalyst and electron energy loss spectroscopy (EELS) mapping showing the distribution of Ni (yellow), Co (blue), C (red) and O (green).

The resulting pyrolyzed $\mathrm{Ni}, \mathrm{Co}$ and bimetallic Ni-Co MOF derived catalysts ( $\mathrm{Ni}, \mathrm{Co}$ and Ni-Co@CMOF-74) exhibited highly dispersed nanoparticles of ca. 5.5, 3.5 and 6 nm (Figure S7) respectively, with overall metal content of $68-69 \mathrm{wt} \%$. Determined by inductively coupled plasma optical emission spectroscopy (ICP-OES; Table 1). STEM-EELS images also revealed uniform distribution of cobalt and nickel particles in the bimetallic system although covered within carbon capsules (Figure 1c), in line with the previous observations of Sun et al. that showed a carbon shell covering Co based MOFs [28]. Additionally, after the pyrolysis and passivation steps, graphite $\left(2 \theta=30.6^{\circ}\right)$ and cubic phase of metallic Ni, Co and Ni-Co ([111] [200] [220] facets $2 \theta=44,52$ and $76^{\circ}$ ) can be detected by x-ray diffraction (Figure 1b). Finally, as expected, the BET values decreased compared to the pristine MOFs (Table 1) with both M-MOF-74 and M@CMOF-74 materials showing a typical Type I sorption isotherm of microporous materials (Figures S1-S6).

To get further insight on the reducibility behavior of these metallic nanoparticles, we performed $\mathrm{H}_{2}$ temperature programed reduction (TPR; Figure S8). We observed a peak at low temperature for Co@CMOF-74 and Ni-Co@MOF-74 catalysts at $230{ }^{\circ} \mathrm{C}$ and $210^{\circ} \mathrm{C}$ respectively, which should correspond to the reduction of $\mathrm{Co}_{3} \mathrm{O}_{4}$ species to $\mathrm{CoO}$, while further heating at $480^{\circ} \mathrm{C}$ leads to subsequent reduction of $\mathrm{CoO}$ to metallic $\mathrm{Co}$ [29]. As for the Ni-Co@MOF-74 sample, a second peak appears at $560{ }^{\circ} \mathrm{C}$ and stands for mixed $\mathrm{CoO}$ and $\mathrm{NiO}$ reduction to metals. On the other hand, Ni@CMOF-74 shows a unique peak at $530{ }^{\circ} \mathrm{C}$, which corresponds to the reduction of $\mathrm{NiO}$ to $\mathrm{Ni}^{0}$ [30].

\subsection{Catalytic DRM Tests}

We first performed a DRM test at atmospheric pressure to establish a reference point for our reaction condition screening. However, none of the MOF mediated catalyst showed any activity. This behavior is in line with the already above discussed work of Sun et al. that claimed the need of a certain pressure to break the inaccessible carbon shell of Co based MOFs [28]. This is also probably the reason why no reports of MOFs mediated materials exists for the dry reforming reaction, despite 
the high momentum of the MOFs mediated synthesis approach. Nevertheless, as we will next show, this drawback can be sorted out if some pressure is applied to the system.

Hence, the following tests on the Ni, Co and Ni-Co@CMOF-74 solids were carried out under 5 bars at $750{ }^{\circ} \mathrm{C}$ and $18 \mathrm{~L} \cdot \mathrm{h}^{-1} \cdot \mathrm{g}^{-1}$ (Figure 2). We could observe that now all samples showed catalytic activity with both $\mathrm{Ni}$ and $\mathrm{Co}$ catalysts deactivating from the first minutes under reaction conditions. This behavior highlights the challenges of the high pressure DRM operation, with pressure build ups in the reactor above 10 bars for both monometallic samples. On the other hand, the bimetallic Ni-Co@CMOF-74 catalyst showed better stability and catalytic performance with no pressure build up for more than $7 \mathrm{~h}$, displaying a $\mathrm{H}_{2} / \mathrm{CO}$ ratio of 0.82 and $\mathrm{CO}_{2}$ and $\mathrm{CH}_{4}$ conversions of $65 \%$ and $57 \%$ respectively. After $10 \mathrm{~h}$ on the stream we could observe the pressure build-up also took place in this bimetallic sample, showing TEM images the formation of whisker carbon plus the sintering of metal nanoparticles (Figure S14). Thermogravimetric analysis (TGA) of the spent catalysts (Figure S15) shows that after these $10 \mathrm{~h}$ on the reaction stream Ni, Co and Ni-Co@CMOF-74 showed 70, 20 and $20 \mathrm{wt} \%$ of formed coke respectively, in line with the better stability of the bimetallic sample observed in Figure 2. However, we need to point out that the presence of carbon in the fresh sample together with the fact that we cannot assure that part of the signal does not come from methane (derived from hydrogenation of the $C$ shell) makes this coke quantification comparison not straightforward.
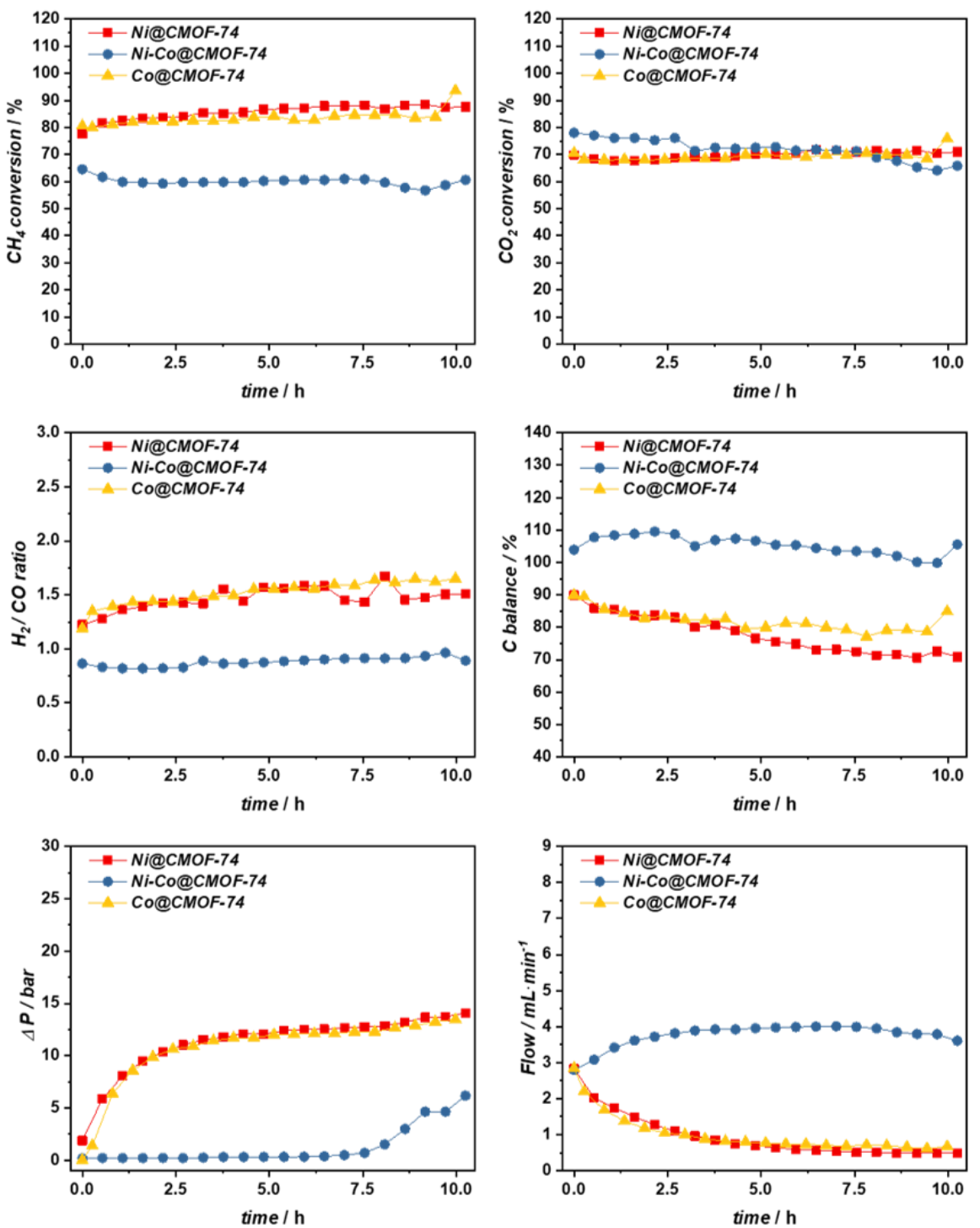

Figure 2. Catalytic results of the different M@CMOF-74 catalysts at $750{ }^{\circ} \mathrm{C}, 5 \mathrm{bar}, 18 \mathrm{~L} \cdot \mathrm{h}^{-1} \cdot \mathrm{g}^{-1}$. 
To unravel the chemical status during reaction we performed X-ray photoelectron spectroscopy (XPS) in both fresh and spent samples (Figure 3 and Figures S16 and S17). According to the data acquired for the fresh catalysts nickel and cobalt are mainly reduced and the main peaks of metals were located at Co 2p $p_{3 / 2} 778.3$ eV (Co0) for Ni-Co@CMOF-74 and Co@CMOF-74, and at Ni 2p $3 / 2852.8$ eV (Ni0) for Ni-Co@CMOF-74 and Ni@CMOF-74. Meanwhile, XPS spectra of the spent samples show the same chemical species of metals for Ni@CMOF-74 and Ni-Co@CMOF-74. In the case of the pure Co@CMOF-74 catalyst after reaction two chemical states were observed with binding energies of Co $2 \mathrm{p}_{3 / 2}$ peak at $778.3 \mathrm{eV}$ and $780.0 \mathrm{eV}$, which correspond to reduced $\mathrm{Co}^{0}$ and $\mathrm{Co}_{3} \mathrm{O}_{4}$, respectively [31]. Deviation of the Co oxidation state for the bimetallic sample also indicates stabilization of metal species with alloy formation. These synergistic effects of Ni-Co within the bimetallic alloy have been identified as key for the coke management in the catalyst and are presumably the cause of the enhanced stability of the bimetallic MOF mediated sample [32,33].
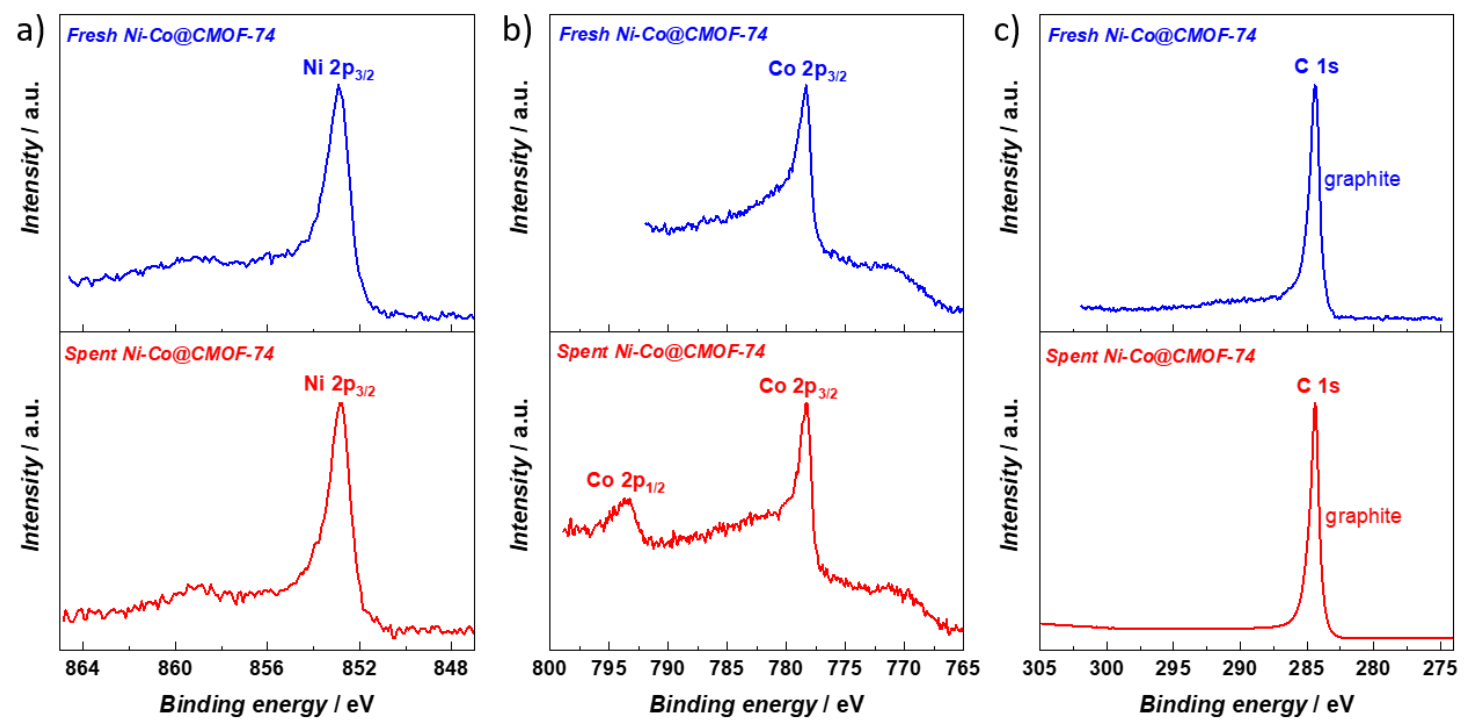

Figure 3. X-ray photoelectron spectroscopy of the Ni-Co@CMOF-74 solid before and after reaction with core levels: (a) $\mathrm{Ni}(2 \mathrm{p}),(\mathbf{b}) \mathrm{Co}(2 \mathrm{p})$ and (c) $\mathrm{C}(1 \mathrm{~s})$.

We next evaluated the effect of different reaction conditions such as pressure, temperature and GHSV. First we studied the effect of the space time by varying the GHSV to 33 and $63 \mathrm{~L} \cdot \mathrm{h}^{-1} \cdot \mathrm{g}^{-1}$ (Figures S9 and S10). We could observe that, as expected, increasing the space time reduces both the $\mathrm{CO}_{2}$ and $\mathrm{CH}_{4}$ conversion, especially at the highest values. In addition, we could observe that the more we increase the space time velocity, the faster the catalyst deactivates and the higher the pressure build up is due to the coke formed in the reactor. Following, we increased the pressure to 10 bars (Figure S11). We could observe that increasing the pressure decreased both $\mathrm{CH}_{4}$ and $\mathrm{CO}_{2}$ conversions, in line with the process thermodynamics [34]. Additionally, the Ni-Co@CMOF-74 bimetallic catalyst was only stable now for $5 \mathrm{~h}$ (in comparison with the $7.5 \mathrm{~h}$ at 5 bars), again in agreement with the theoretically proposed enhanced coke formation when the pressure increased [35]. Finally, we evaluated the effect of the reaction temperature $\left(700\right.$ and $800{ }^{\circ} \mathrm{C}$, Figures S12 and S13 respectively). We could observe that increasing the temperature to $800^{\circ} \mathrm{C}$ drastically reduced the catalyst stability, with all samples deactivating in no time. On the other hand, at lower temperatures $\left(700^{\circ} \mathrm{C}\right)$ the Ni-Co@CMOF-74 bimetallic shows no sign of deactivation while the monometallic Ni@CMOF-74 and Co@CMOF-74 samples only lasted a few hours on the stream before they suffered extreme coking that led to the reactor pressure build up (Figure S12). Hence, despite the observed challenges, there was still room for DRM at high pressure with our bimetallic Ni-Co MOF mediated catalyst that displayed stable performance during at least $10 \mathrm{~h}$ at $700{ }^{\circ} \mathrm{C}, 5 \mathrm{bar}$ and $33 \mathrm{~L} \cdot \mathrm{h}^{-1} \cdot \mathrm{g}^{-1}$. 
Finally, the performance of our Ni-Co@CMOF-74 catalyst was compared with the state of the art carbon-supported nickel catalysts for the DRM reaction (Table S1) [36-38]. We could observe that, despite the high pressure used in this work that limits the equilibrium yields [34], our catalyst system showed equivalent levels of conversions of $\mathrm{CH}_{4}$ and $\mathrm{CO}$. Moreover, the Ni-Co@CMOF-74 catalyst showed a stable performance for longer periods without appreciable induction.

\section{Materials and Methods}

2,5-dihydroxyterephthalic acid was purchased from Fisher Scientific. Sodium hydroxide, cobalt acetate hexahydrate and nickel acetate hexahydrate were purchased from Sigma-Aldrich and were used as received unless noted.

The synthesis of the parent MOFs was done by mixing of $3.6 \mathrm{mmol}$ of metal sources dissolved in $60 \mathrm{~mL}$ of distilled water with $1.7 \mathrm{mmol}$ DHTA and $7.2 \mathrm{mmol} \mathrm{NaOH}$ dissolved in $20 \mathrm{~mL}$ of distilled water with the overall ratio $2 / 1 / 4$. The final mixture was kept overnight under stirring at room temperature. The mixture was washed 3 times with water, 3 times with methanol and left overnight in methanol. Afterwards, the powder was washed 1 more time with methanol filtrated and dried in the oven at $60^{\circ} \mathrm{C}$

The carbonization of MOFs was conducted in a quartz tubular reactor vertically placed in a tube furnace. In a typical experiment, M-MOF-74 were placed in the reactor under continuous flow of $\mathrm{N}_{2}$ followed by direct carbonization at different temperature for $8 \mathrm{~h}$ under $\mathrm{N}_{2}\left(25 \mathrm{~mL} \mathrm{~min}^{-1}\right)$ using a heating ramp of $2{ }^{\circ} \mathrm{C} \mathrm{min}-1$. After cooling down of the reactor the samples were passivated in the continuous flow of $\mathrm{N}_{2}\left(25 \mathrm{~mL} \mathrm{~min}^{-1}\right)$ and oxygen $\left(5 \mathrm{~mL} \mathrm{~min}^{-1}\right)$ for $2 \mathrm{~h}$.

Reaction tests were conducted in a 4-channel Flowrence XD platform from Avantium. Typically, presieved $10 \mathrm{mg}$ of the catalyst was loaded in stainless steel reactors. As a first step $\mathrm{Ar}\left(5 \mathrm{~mL} \mathrm{~min}{ }^{-1}\right)$ pretreatment at the temperature of the reaction was conducted for $4 \mathrm{~h}$ under reaction pressure. The mixed feed consisted of $1 / 1 / 1$ ratio of $\mathrm{CH}_{4} / \mathrm{CO}_{2} / \mathrm{N}_{2}$. In addition, $2 \mathrm{~mL} \mathrm{~min}{ }^{-1}$ of He was mixed with the feed as the internal standard. The catalysts that were in powder form were pressed into pellets at 4 ton $\left(\mathrm{m}^{2}\right)^{-1}$ for $5 \mathrm{~min}$. The pellets were crushed and sieved to obtain grains sized from 150 to $250 \mu \mathrm{m}$.

The $\mathrm{N}_{2}$ adsorption-desorption isotherms were carried out at $77 \mathrm{~K}$ using a Micromeritics ASAP 2040 instrument. Before the measurement, samples were degassed at $150{ }^{\circ} \mathrm{C}$ for $8 \mathrm{~h}$.

The powder X-ray diffraction (PXRD) analysis were carried out using a Bruker D8 advanced diffractometer in Bragg-Brentano geometry fitted with a copper tube operating at $40 \mathrm{kV}$ and $40 \mathrm{~mA}$. The diffractograms were acquired over the $2 \theta$ range of $5-50^{\circ}$ and $10-80^{\circ}$, using a step size of $0.014^{\circ}$ with a timestep of $5 \mathrm{~s}$.

Thermogravimetric (TG) data were collected air atmospheres using a Mettler-Toledo thermal analyzer at a heating rate of $5{ }^{\circ} \mathrm{C} \cdot \mathrm{min}^{-1}$ in the $25-900{ }^{\circ} \mathrm{C}$ temperature range and a gas flow of $25 \mathrm{~mL} \cdot \mathrm{min}^{-1}$.

Transmission electron microscopy (TEM) was performed on a Tecnai-Twin system at $120 \mathrm{kV}$. Samples were dispersed in chloroform before placing them on the TEM grid. Annular dark-field scanning transmission electron microscopy (ADF-STEM) analysis and EELS elemental mapping of the samples were carried out with an FEI Titan G 2 80-300 kV electron microscope operated at $300 \mathrm{kV}$ in the STEM mode.

Inductive coupled plasma (ICP) analysis was carried out in 5100 ICP-OES instrument (Agilent) and SPS 4 Autosampler (Agilent) with Ar being used as a gas supply. Digestion was done at max $240{ }^{\circ} \mathrm{C}$ and max 35 bar using UltraWAVE apparatus (Milestone) with Aqua regia for MOFs and Aqua regia + HF solution for carbonized samples. Prior to digestion of the samples, the vessel cleaning step was performed using only nitric acid $(5 \mathrm{~mL})$. A calibration curve (4 plots) was built (1-10-25-100 $\mathrm{ppm}$ ) and all samples were duplicated. Moreover, laboratory reagent blank (LRB), laboratory fortified blank (LFB), quality control sample (QCS) and continuing calibration verification (CCV) samples were recorded to validate the results as recommended in several standard methods 
$\mathrm{H}_{2}$-TPR was carried out in AutoChem $2950 \mathrm{HP}$ Chemsorption Analyzer. Prior to the measurements, each sample was pretreated in $\mathrm{Ar}$ at $200^{\circ} \mathrm{C}$ for $20 \mathrm{~min}$ to remove adsorbed species. The measurements were done in $10 \% \mathrm{H}_{2} / \mathrm{Ar}$ mixture with a total flow of $50 \mathrm{~mL} \mathrm{~min}{ }^{-1}$ and a heating rate of $5{ }^{\circ} \mathrm{C} \cdot \mathrm{min}^{-1}$.

$\mathrm{X}$-ray photoelectron spectroscopy (XPS) was carried out in a EnviroESCA spectrometer (SPECS $\mathrm{GmbH})$ equipped with a monochromatic AlK $\alpha$ x-ray source $(\mathrm{h} v=1486.6 \mathrm{eV})$ operating at $42 \mathrm{~W}$ and X-Ray emission $3.00 \mathrm{~mA}$, an acquisition of spectra was performed under an ultra-high vacuum conditions $\left(10^{-8}-10^{-9} \mathrm{mbar}\right)$. Spectra were collected at a fixed analyzer pass energy $20 \mathrm{eV}$. Photoelectron peak C 1s (284.4 eV for sp2 graphite carbon species) was used for a binding energy correction. Typically, powder samples was immobilized on the Cu conductive tape (SPI supplies, Structure Probe, Inc., West Chester, PA, USA), placed on the sample holder and evacuated until ultra-high vacuum was reached.

\section{Conclusions}

In conclusion, we demonstrated that the rational selection of the highly tunable MOF-74 allowed the synthesis of different carbon-supported Ni, Co and Ni-Co bimetallic catalysts. This approach allows synthesizing bimetallic systems with high metal content uniformly distributed inside of graphitic carbon shell. The bimetallic Ni-Co@CMOF-74 catalyst showed better catalytic results in comparison with monometallic materials due to the synergistic effect of $\mathrm{Ni}$ and $\mathrm{Co}$ that impedes the coke formation. To be more specific, stable performance for least $10 \mathrm{~h}$ at $700{ }^{\circ} \mathrm{C}, 5 \mathrm{bar}$ and $33 \mathrm{~L} \cdot \mathrm{h}^{-1} \cdot \mathrm{g}^{-1}$ was found for the Ni-Co@CMOF-74 catalyst in contrast with the fast deactivation observed for the monometallic counterparts. Our finding demonstrated that MOF mediated catalysts have potential application in DRM at high pressure. We hope that these results will encourage researchers for the further development of MOF mediated systems, not only for DRM but also for further catalytic applications.

Supplementary Materials: Supplementary Materials are available online at http://www.mdpi.com/2073-4344/10/5/592/ s1. Figure S1. (a) N2 adsorption isotherm at 77 K, (b) Rouquerol plot and (c) Brunauer-Emmett-Teller (BET) fit for Ni-MOF-74. Figure S2. (a) N2 adsorption isotherm at 77 K, (b) Rouquerol plot and (c) Brunauer-Emmett-Teller (BET) fit for Co-MOF-74. Figure S3. (a) N2 adsorption isotherm at 77 K, (b) Rouquerol plot and (c) Brunauer-Emmett-Teller (BET) fit for Ni-Co-MOF-74. Figure S4. (a) N2 adsorption isotherm at $77 \mathrm{~K}$, (b) Rouquerol plot and (c) Brunauer-Emmett-Teller (BET) fit for Ni@CMOF-74. Figure S5. (a) N2 adsorption isotherm at 77 K, (b) Rouquerol plot and (c) Brunauer-Emmett-Teller (BET) fit for Co@CMOF-74. Figure S6. (a) N2 adsorption isotherm at 77 K, (b) Rouquerol plot and (c) Brunauer-Emmett-Teller (BET) fit for Ni-Co@MOF-74. Figure S7. TEM images and MNP size distribution of the different M@CMOF-74 catalysts. Figure S8. Temperature programed reduction (TPR) profiles of the different M@CMOF-74 catalysts. Figure S9. Catalytic results of the different M@CMOF-74 catalysts at $750{ }^{\circ} \mathrm{C}, 5 \mathrm{bar}, 33 \mathrm{~L}{ }^{*} \mathrm{~h}-1^{*} \mathrm{~g}-1$. Figure S10. Catalytic results of the different M@CMOF-74 catalysts at $750{ }^{\circ} \mathrm{C}, 5$ bar, $63 \mathrm{~L} * \mathrm{~h}-1^{*} \mathrm{~g}-1$. Figure S11. Catalytic results of the different M@CMOF-74 catalysts at $750{ }^{\circ} \mathrm{C}, 10 \mathrm{bar}$, $33 \mathrm{~L} * \mathrm{~h}-1^{*} \mathrm{~g}-1$. Figure S12. Catalytic results of the different M@CMOF-74 catalysts at $700{ }^{\circ} \mathrm{C}, 5 \mathrm{bar}, 33 \mathrm{~L} * \mathrm{~h}-1^{*} \mathrm{~g}-1$. Figure S13. Catalytic results of the different M@CMOF-74 catalysts at $800{ }^{\circ} \mathrm{C}, 5 \mathrm{bar}, 33 \mathrm{~L} * \mathrm{~h}-1^{*} \mathrm{~g}-1$. Figure S14. High-resolution dark field STEM images of spent Ni-Co@CMOF-74 catalyst and STEM-EELS mapping showing the distribution of $\mathrm{Ni}$ (yellow), $\mathrm{Co}$ (blue), $\mathrm{C}$ (red) and $\mathrm{O}$ (green) throughout the solid after 10 hours of reaction. Reaction condition: $750^{\circ} \mathrm{C}, 5$ bar and $33 \mathrm{~L}{ }^{*} \mathrm{~h}-1^{*} \mathrm{~g}-1$. Figure S15. Thermogravimetric curves for the fresh (left) and spent (right) M@CMOF-74 catalysts in air. Figure S16. X-ray photoelectron spectroscopy of the Ni@CMOF-74 solid before and after reaction with core levels $(\mathrm{a}) \mathrm{Ni}(2 \mathrm{p})$ and (b) $\mathrm{C}(1 \mathrm{~s})$. Figure S17. X-ray photoelectron spectroscopy of the Co@CMOF-74 solid before and after reaction with core levels (a) $\mathrm{Co}(2 \mathrm{p})$ and (b) C(1s). Table S1. Comparison of Carbon supported materials for the DRM reported in literature with the Ni-Co@CMOF-74 catalyst.

Author Contributions: Conceptualization, A.R., L.G.-T. and J.G.; catalyst synthesis, I.S.K. and L.G.-T.; catalyst characterization, G.S., I.S.K. and L.G.-T.; catalyst testing, I.S.K. and A.R..; supervision, J.G.; project administration, J.G.; All authors have contributed to the writing of the manuscript and read and agreed to the published version of the manuscript.

Funding: Funding for this work was provided by King Abdullah University of Science and Technology (KAUST). Conflicts of Interest: The authors declare no conflict of interest.

\section{References}

1. Mac Dowell, N.; Fennell, P.; Shah, N.; Maitland, G. The role of $\mathrm{CO}_{2}$ capture and utilization in mitigating climate change. Nat. Clim. Chang. 2017, 7, 243-249. [CrossRef] 
2. Shih, C.F.; Zhang, T.; Li, J.; Bai, C. Powering the Future with Liquid Sunshine. Joule 2018, 2, $1925-1949$. [CrossRef]

3. Bradford, M.C.J.; Vannice, M.A. $\mathrm{CO}_{2}$ Reforming of $\mathrm{CH}_{4}$. Catal. Rev. 1999, 41, 1-42. [CrossRef]

4. Pakhare, D.; Spivey, J.J. A review of dry $\left(\mathrm{CO}_{2}\right)$ reforming of methane over noble metal catalysts. Chem. Soc. Rev. 2014, 43, 7813-7837. [CrossRef]

5. Dokania, A.; Ramirez, A.; Bavykina, A.V.; Gascon, J. Heterogeneous Catalysis for the Valorization of $\mathrm{CO}_{2}$ : Role of Bifunctional Processes in the Production of Chemicals. ACS Energy Lett. 2018, 4, 167-176. [CrossRef]

6. Tsang, S.; Claridge, J.B.; Green, M. Recent advances in the conversion of methane to synthesis gas. Catal. Today 1995, 23, 3-15. [CrossRef]

7. Edwards, J.; Maitra, A. The chemistry of methane reforming with carbon dioxide and its current and potential applications. Fuel Process. Technol. 1995, 42, 269-289. [CrossRef]

8. Zhang, J.; Wang, H.; Dalai, A. Development of stable bimetallic catalysts for carbon dioxide reforming of methane. J. Catal. 2007, 249, 300-310. [CrossRef]

9. Takanabe, K.; Nagaoka, K.; Nariai, K.; Aika, K. Titania-supported cobalt and nickel bimetallic catalysts for carbon dioxide reforming of methane. J. Catal. 2005, 232, 268-275. [CrossRef]

10. Song, Y.; Ozdemir, E.; Ramesh, S.; Adishev, A.; Subramanian, S.; Harale, A.; AlBuali, M.; Fadhel, B.A.; Jamal, A.; Moon, D.; et al. Dry reforming of methane by stable Ni-Mo nanocatalysts on single-crystalline MgO. Science 2020, 367, 777-781. [CrossRef]

11. Ramirez, A.; Gascon, J. Support Was the Key to Success. Joule 2020. [CrossRef]

12. Kaur, H.; Sundriyal, S.; Pachauri, V.; Ingebrandt, S.; Kim, K.-H.; Sharma, A.L.; Deep, A. Luminescent metal-organic frameworks and their composites: Potential future materials for organic light emitting displays. Coord. Chem. Rev. 2019, 401, 213077. [CrossRef]

13. Lin, R.-B.; Xiang, S.; Zhou, W.; Chen, B. Microporous Metal-Organic Framework Materials for Gas Separation. Chem 2020, 6, 337-363. [CrossRef]

14. Jiao, L.; Wang, Y.; Jiang, H.-L.; Xu, Q. Metal-Organic Frameworks as Platforms for Catalytic Applications. Adv. Mater. 2017, 30, 1703663. [CrossRef] [PubMed]

15. Rao, P.C.; Mandal, S. Potential Utilization of Metal-Organic Frameworks in Heterogeneous Catalysis: A Case Study of Hydrogen-Bond Donating and Single-Site Catalysis. Chem. Asian J. 2019, 14, 4087-4102. [CrossRef]

16. Mukherjee, S.; Zaworotko, M.J. Crystal Engineering of Hybrid Coordination Networks: From Form to Function. TrAC Trends Anal. Chem. 2020. [CrossRef]

17. Kirchon, A.; Feng, L.; Drake, H.F.; Joseph, E.; Zhou, H.-C. From fundamentals to applications: A toolbox for robust and multifunctional MOF materials. Chem. Soc. Rev. 2018, 47, 8611-8638. [CrossRef]

18. Oar-Arteta, L.; Wezendonk, T.; Sun, X.; Kapteijn, F.; Gascon, J. Metal organic frameworks as precursors for the manufacture of advanced catalytic materials. Mater. Chem. Front. 2017, 1, 1709-1745. [CrossRef]

19. Long, J.; Shen, K.; Chen, L.; Li, Y. Multimetal-MOF-derived transition metal alloy NPs embedded in an N-doped carbon matrix: Highly active catalysts for hydrogenation reactions. J. Mater. Chem. A 2016, 4, 10254-10262. [CrossRef]

20. Li, S.; Wang, N.; Yue, Y.; Wang, G.; Zu, Z.; Zhang, Y. Copper doped ceria porous nanostructures towards a highly efficient bifunctional catalyst for carbon monoxide and nitric oxide elimination. Chem. Sci. 2015, 6, 2495-2500. [CrossRef]

21. Wu, X.-Q.; Zhao, J.; Wu, Y.-P.; Dong, W.-W.; Li, D.-S.; Li, J.-R.; Zhang, Q. Ultrafine Pt Nanoparticles and Amorphous Nickel Supported on 3D Mesoporous Carbon Derived from Cu-Metal-Organic Framework for Efficient Methanol Oxidation and Nitrophenol Reduction. ACS Appl. Mater. Interfaces 2018, 10, 12740-12749. [CrossRef] [PubMed]

22. Lippi, R.; Howard, S.; Escobar, H.B.; Easton, C.D.; Madsen, I.C.; Waddington, L.J.; Vogt, C.; Hill, M.R.; Sumby, C.J.; Doonan, C.J.; et al. Highly active catalyst for $\mathrm{CO}_{2}$ methanation derived from a metal organic framework template. J. Mater. Chem. A 2017, 5, 12990-12997. [CrossRef]

23. Santos, V.P.; Wezendonk, T.A.; Jaén, J.J.D.; Dugulan, A.I.; Nasalevich, M.A.; Islam, H.-U.; Chojecki, A.; Sartipi, S.; Sun, X.; Hakeem, A.A.; et al. Metal organic framework-mediated synthesis of highly active and stable Fischer-Tropsch catalysts. Nat. Commun. 2015, 6, 6451. [CrossRef] [PubMed]

24. Fidalgo, B.; Zubizarreta, L.; Bermúdez, J.M.; Arenillas, A.; Menéndez, J.A. Synthesis of carbon-supported nickel catalysts for the dry reforming of $\mathrm{CH}_{4}$. Fuel Process. Technol. 2010, 91, 765-769. [CrossRef] 
25. Fidalgo, B.; Arenillas, A.; Menéndez, J.A. Synergetic effect of a mixture of activated carbon $+\mathrm{Ni} / \mathrm{Al}_{2} \mathrm{O}_{3}$ used as catalysts for the $\mathrm{CO}_{2}$ reforming of $\mathrm{CH}_{4}$. Appl. Catal. A Gen. 2010, 390, 78-83. [CrossRef]

26. Wang, L.J.; Deng, H.; Furukawa, H.; Gándara, F.; Cordova, K.E.; Peri, D.; Yaghi, O.M. Synthesis and Characterization of Metal-Organic Framework-74 Containing 2, 4, 6, 8, and 10 Different Metals. Inorg. Chem. 2014, 53, 5881-5883. [CrossRef] [PubMed]

27. Garzón-Tovar, L.; Carne-Sanchez, A.; Carbonell, C.; Imaz, I.; Maspoch, D. Optimised room temperature, water-based synthesis of CPO-27-M metal-organic frameworks with high space-time yields. J. Mater. Chem. A 2015, 3, 20819-20826. [CrossRef]

28. Sun, X.; Olivos-Suarez, A.; Oar-Arteta, L.; Rozhko, E.; Osadchii, D.; Bavykina, A.V.; Kapteijn, F.; Gascon, J. Metal-Organic Framework Mediated Cobalt/Nitrogen-Doped Carbon Hybrids as Efficient and Chemoselective Catalysts for the Hydrogenation of Nitroarenes. Chem CatChem 2017, 9, 1854-1862. [CrossRef]

29. Lin, H.-K.; Chiu, H.-C.; Tsai, H.-C.; Chien, S.-H.; Wang, C.-B. Synthesis, Characterization and Catalytic Oxidation of Carbon Monoxide over Cobalt Oxide. Catal. Lett. 2003, 88, 169-174. [CrossRef]

30. Jehng, J.-M.; Chen, C.-M. Amination of Polyethylene Glycol to Polyetheramine over the Supported Nickel Catalysts. Catal. Lett. 2001, 77, 147-154. [CrossRef]

31. Rumble, J.R.; Bickham, D.M.; Powell, C.J. The NIST x-ray photoelectron spectroscopy database. Surf. Interface Anal. 1992, 19, 241-246. [CrossRef]

32. Li, L.; Anjum, D.H.; Zhu, H.; Saih, Y.; Laveille, P.; D'Souza, L.; Basset, J.-M. Synergetic Effects Leading to Coke-Resistant NiCo Bimetallic Catalysts for Dry Reforming of Methane. ChemCatChem 2015, 7, 427-433. [CrossRef]

33. Aramouni, N.A.K.; Touma, J.G.; Abu Tarboush, B.; Zeaiter, J.; Ahmad, M. Catalyst design for dry reforming of methane: Analysis review. Renew. Sustain. Energy Rev. 2018, 82, 2570-2585. [CrossRef]

34. Chein, R.; Chen, Y.; Yu, C.; Chung, J. Thermodynamic analysis of dry reforming of $\mathrm{CH}_{4}$ with $\mathrm{CO}_{2}$ at high pressures. J. Nat. Gas Sci. Eng. 2015, 26, 617-629. [CrossRef]

35. Schulz, L.A.; Kahle, L.C.; Delgado, K.H.; Schunk, S.A.; Jentys, A.; Deutschmann, O.; Lercher, J.A. On the coke deposition in dry reforming of methane at elevated pressures. Appl. Catal. A Gen. 2015, 504, 599-607. [CrossRef]

36. Ma, Q.; Wang, D.; Wu, M.; Zhao, T.; Yoneyama, Y.; Tsubaki, N. Effect of catalytic site position: Nickel nanocatalyst selectively loaded inside or outside carbon nanotubes for methane dry reforming. Fuel 2013, 108, 430-438. [CrossRef]

37. Xu, L.; Liu, Y.; Li, Y.; Lin, Z.; Ma, X.; Zhang, Y.; Argyle, M.D.; Fan, M. Catalytic $\mathrm{CH}_{4}$ reforming with $\mathrm{CO}_{2}$ over activated carbon based catalysts. Appl. Catal. A Gen. 2014, 469, 387-397. [CrossRef]

38. Zhang, G.; Su, A.; Du, Y.; Qu, J.; Xu, Y. Catalytic performance of activated carbon supported cobalt catalyst for $\mathrm{CO}_{2}$ reforming of $\mathrm{CH}_{4}$. J. Colloid Interface Sci. 2014, 433, 149-155. [CrossRef] [PubMed] 